\title{
Stereoelectronic Effects on the Binding of Neutral Lewis Bases to CdSe Nanocrystals
}

Nicholas C. Anderson, Peter. E. Chen, Aya K. Buckley, Jonathan De Roo, Jonathan S. Owen* Department of Chemistry, Columbia University, New York, New York, 10027.

Email: jso2115@columbia.edu, Telephone: (212) 851-5879 


\begin{abstract}
Using ${ }^{31} \mathrm{P}$ nuclear magnetic resonance (NMR) spectroscopy, we monitor the competition between tri- $n$-butylphosphine $\left(\mathrm{Bu}_{3} \mathrm{P}\right)$ and various amine and phosphine ligands for the surface of chloride terminated CdSe nanocrystals. Distinct ${ }^{31} \mathrm{P}$ NMR signals for free and bound phosphine ligands allow their surface coverages to be directly measured. Ligands with a small steric profile achieve higher surface coverages $\left(\mathrm{Bu}_{3} \mathrm{P}=0.5 \mathrm{~nm}^{-2}, \mathrm{Me}_{2} \mathrm{P}-n\right.$-octyl $\left.=2.0 \mathrm{~nm}^{-2}, \mathrm{NH}_{2} \mathrm{Bu}=3-4 \mathrm{~nm}^{-2}\right)$ and have greater relative binding affinity $\left(K_{r e l}\right)$ for the nanocrystal $\left(K_{r e l}\right.$ : $\mathrm{Me}_{3} \mathrm{P}>\mathrm{Me}_{2} \mathrm{P}-n$-octyl $\sim \mathrm{Me}_{2} \mathrm{P}-n$ octadecyl $\left.>\mathrm{Et}_{3} \mathrm{P}>\mathrm{Bu}_{3} \mathrm{P}\right)$. The affinity of amine ligands is measured by the extent of $\mathrm{Bu}_{3} \mathrm{P}$ displacement from the nanocrystals in the presence of 1 or 50 equiv of competing ligand $\left(K_{\text {rel }}\right.$ : $\mathrm{H}_{2} \mathrm{NBu} \sim N$ - $n$-butylimidazole $>$ 4-ethylpyridine $>\mathrm{Bu}_{3} \mathrm{P} \sim \mathrm{HNBu}_{2}>\mathrm{Me}_{2} \mathrm{NBu}>\mathrm{Bu}_{3} \mathrm{~N}$ ). The affinity for the CdSe surface is greatest for soft, basic donors and also depends on the number of each ligand that bind. Sterically unencumbered ligands such as imidazole, pyridine, and $n$-alkylamines can therefore outcompete stronger donors such as alkylphosphines. The influence of repulsive interactions between ligands on the binding affinity is a consequence of the high atom density of binary semiconductor surfaces. The situation is distinct from the self-assembly of straight chain surfactants on gold and silver where the ligands are commensurate with the underlying lattice and attractive interactions between ligands strengthen the binding.
\end{abstract}

\title{
Introduction
}

The photoluminescence quantum yield and chemical stability of II-VI semiconductor nanocrystals (NCs) depends critically on the binding affinity of their surface ligands.(1) A deeper understanding of surface coordination chemistry would aid the design of ligands that effectively stabilize NCs in cellular environments and solid state lighting applications, while maximizing their photoluminescence quantum yield (PLQY). However, few methods directly monitor ligand binding to surfaces. Photoluminescence spectroscopy has been used to study the binding of amines and phosphines to $\mathrm{CdSe} \mathrm{NCs}(2-10)$ and bulk $\mathrm{CdSe}(11-13)$ surfaces, where ligand binding can raise (or lower) the PLQY. For example, changes to PLQY of a single crystal placed in an atmosphere of gaseous amine were analyzed using the Langmuir model.(11-13) Binding constants were extracted $\left(\mathrm{H}_{3} \mathrm{~N}<\mathrm{H}_{2} \mathrm{NMe}<\mathrm{HNMe}_{2}>\mathrm{NMe}_{3}\right)$ that parallel the gas phase proton affinity of the amine (with the exception of $\mathrm{NMe}_{3}$ ). A similar strategy was used to analyze ligand binding to colloidal CdSe NCs in solution.(14) In both cases, the PLQY is assumed to be proportional to the fractional 
surface coverage, which ignores several complications including changes to the recombination mechanism,(9) side reactions involving acidic impurities(15) or displacement of atoms from the crystal surface.(16) In the case of single crystals, the method convolves the ligand donor strength and surface coverage. Moreover, adsorption isotherms, such as the Langmuir model, do not account for steric interactions between ligands that reduce the number of accessible surface sites.(13) As a result, there is not a clear understanding of the stereo-electronic factors that determine surface binding affinity of simple donor ligands, nor how to explain affinities that do not follow the ligand donor strength (e.g. $\mathrm{HNMe}_{2}>\mathrm{NMe}_{3}$ ), or the relatively weak binding affinity of $N, N, N^{\prime}, N^{\prime}-$ tetramethylethylenediamine(16) and bis(diphenylphosphine)ethane(13), both of which are strong donors and have the potential ability to chelate the surface.

Nuclear magnetic resonance (NMR) spectroscopy provides a quantitative method to directly monitor ligand binding to colloidal nanocrystals. The NMR linewidth and chemical shift can distinguish ligands bound to the NC surface from those freely diffusing in solution. Particularly for anionic ligands, which undergo exchange relatively slowly, ligand exchange and binding can be assessed quantitatively.(17-19) NMR spectroscopy has been less useful for studying the exchange of neutral two electron donor ligands, e.g. $n$-alkylamines (L-type ligands)(20-22) because they undergo rapid self-exchange that causes coalescence of signals from free and bound ligands.(23, 24) We previously reported the synthesis of CdSe NCs with both tri- $n$-butylphosphine $\left(\mathrm{Bu}_{3} \mathrm{P}\right)$ and tri- $n$-butylphosphonium chloride $\left(\left[\mathrm{Bu}_{3} \mathrm{P}-\mathrm{H}^{+}\right]\left[\mathrm{Cl}^{-}\right]\right)$ligands $\left(\mathbf{C d S e}-\mathbf{C d C l} \mathbf{C} / \mathbf{B u} \mathbf{P} /[\mathbf{B u} \mathbf{P}-\mathbf{H}]^{+}[\mathbf{C l}]^{-}\right)$ from carboxylate terminated $\mathrm{CdSe} \mathrm{NCs}\left(\mathbf{C d S e}-\mathbf{C d}\left(\mathbf{O}_{2} \mathbf{C R}\right)_{2}\right)_{\text {, and }}$ chlorotrimethylsilane $\left(\mathrm{Me}_{3} \mathrm{SiCl}\right) .(25)$ At room temperature the exchange of the phosphine ligands is slow, and distinct ${ }^{31} \mathrm{P}$ NMR signals for bound and free $\mathrm{Bu}_{3} \mathrm{P}$ are observed. This presents the opportunity to directly monitor the displacement of the $\mathrm{Bu}_{3} \mathrm{P}$ ligands from the nanocrystal surface and to study the stereoelectronic factors that control the surface binding affinity of L-type ligands. 


\section{Results}

To simplify our study, we first eliminate the oleic acid impurity that produces $\left[\mathrm{Bu}_{3} \mathrm{P}-\mathrm{H}^{+}\right]\left[\mathrm{Cl}^{-}\right]$ by pretreatment of the $\mathrm{NCs}$ with $\mathrm{Me}_{2} \mathrm{Cd}$ according to a previously described method (Scheme 1).(15) After removing the solvent and any unreacted $\mathrm{Me}_{2} \mathrm{Cd}$ under vacuum, the NCs were reacted with $\mathrm{Me}_{3} \mathrm{SiCl}$ and $\mathrm{Bu}_{3} \mathrm{P}$ to remove the carboxylate ligands.(26) Unlike $\mathbf{C d S e}-\mathbf{C d C l}_{2} / \mathbf{B u} 3 \mathbf{P} /\left[\mathbf{B u} \mathbf{u}_{3} \mathbf{P}\right.$ $\mathbf{H}]^{+}[\mathbf{C l}]^{-}$, which precipitates from pentane solution, $\mathbf{C d S e}-\mathbf{C d C l}_{2} / \mathbf{B u} 3 \mathbf{P}$ is soluble in pentane and precipitates from methyl acetate or acetonitrile. $\mathrm{A}^{31} \mathrm{P}$ NMR spectrum verifies that the isolated NCs are free from $\left[\mathrm{Bu}_{3} \mathrm{P}-\mathrm{H}\right]^{+}[\mathrm{Cl}]^{-}(\delta=11 \mathrm{ppm})$.

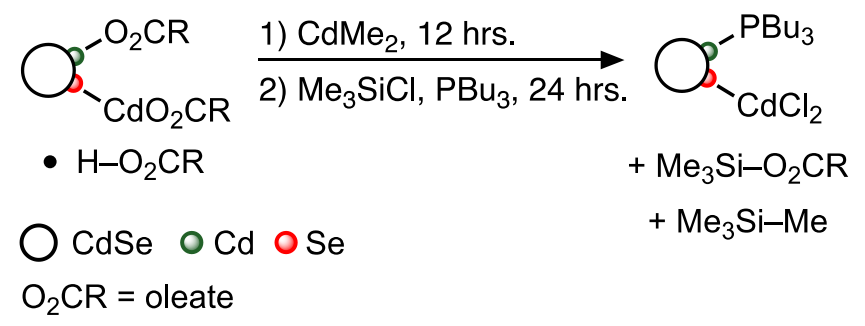

Scheme 1. Synthesis of $\mathbf{C d S e}-\mathbf{C d C l} / \mathbf{B u}_{3} \mathbf{P}$ free of $\left[\mathrm{Bu}_{3} \mathrm{PH}^{+}\right]\left[\mathrm{Cl}^{-}\right]$.

To estimate the relative binding affinity of several L-type ligands, we monitored their ability to displace $\mathrm{Bu}_{3} \mathrm{P}$ from $\mathbf{C d S e}-\mathbf{C d C l}_{2} / \mathbf{B u} \mathbf{P}$ (Figures $\left.\mathrm{S} 1-\mathrm{S} 11\right)$. For example, surface bound $\mathrm{Bu}_{3} \mathrm{P}(\delta=$ $-11 \mathrm{ppm})$ is liberated as $n$-octylamine is added $(0-10$ equiv./Bu $3 \mathrm{P})$ (Figure 1$) .(27) 5-10$ equiv. of $n$-octylamine completely displaces $\mathrm{Bu}_{3} \mathrm{P}$ from the nanocrystal resulting in the sharp signal of a freely diffusing $\mathrm{Bu}_{3} \mathrm{P}$ molecule $(\delta=-31 \mathrm{ppm})$. The relative surface binding affinities of the amines could be ranked by comparing the amount of $\mathrm{Bu}_{3} \mathrm{P}$ displaced in the presence of tri- $n$-alkyl, di- $n$ alkyl, and $n$-alkylamines ( 1 or 50 equiv. / $\mathrm{Bu}_{3} \mathrm{P}$ ). One equiv. of $n$-butylamine more effectively displaces $\mathrm{Bu}_{3} \mathrm{P}$ than does di- $n$-butylamine which is more effective than tri- $n$-butylamine. Amines with methyl substituents displace more $\mathrm{Bu}_{3} \mathrm{P}$ than amines with long chain substituents (e.g. affinity of $\mathrm{Me}_{2} \mathrm{NBu}>\mathrm{Bu}_{3} \mathrm{~N}$ ). These substituent effects do not follow the gas phase proton affinities nor the 
$p K_{a}$ of the conjugate acids $\left(p K_{\mathrm{a}}\left(\mathrm{R}_{3} \mathrm{~N}-\mathrm{H}^{+}\right)\right)$, which are within $1 p K_{a}$ unit in water.(28) Instead they can be explained by the relative steric bulk, with the bulkiest ligands being the weakest competitors.

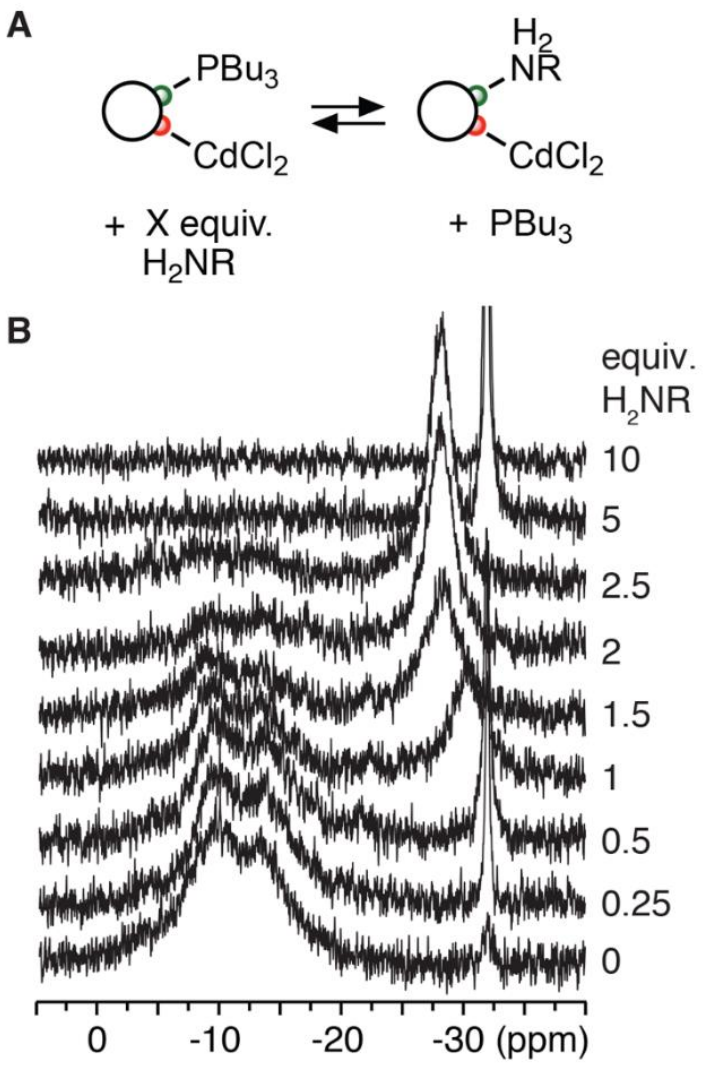

Figure 1. A.) L-type ligand exchange with $\mathbf{C d S e}-\mathbf{C d C l}_{2} / \mathbf{B u}_{3} \mathbf{P}$ designating the ${ }^{31} \mathrm{P}$ NMR handle. B.) A series of ${ }^{31} \mathrm{P}$ NMR spectra of $\mathrm{CdSe}-\mathrm{CdCl}_{2} / \mathrm{Bu}_{3} \mathrm{P}$ with increasing equivalents of $n$ octylamine in benzene- $d_{6}$.

Similar effects were observed upon titration with tri- $n$-alkyphosphines, although in this case the surface coverage of both the incoming and outgoing ligands could be extracted from the ${ }^{31} \mathrm{P}$ NMR spectrum. In the presence of 1 equiv. of triethylphosphine $\left(\mathrm{Et}_{3} \mathrm{P}, \delta=-19 \mathrm{ppm}\right), \mathrm{Bu}_{3} \mathrm{P}$ is displaced from the surface and the broad signal from bound phosphines shifts downfield by $5-10 \mathrm{ppm}$ (Figure 2). Although signals for bound $\mathrm{Bu}_{3} \mathrm{P}$ and $\mathrm{Et}_{3} \mathrm{P}$ overlap, their surface coverages may be determined from the amount of $\mathrm{Bu}_{3} \mathrm{P}$ and $\mathrm{Et}_{3} \mathrm{P}$ that remain free. Interestingly, in the presence of $\mathrm{Et}_{3} \mathrm{P}$ (1 equiv.) the total number of bound phosphines increases from $30 \pm 5 \mathrm{Bu}_{3} \mathrm{P} / \mathrm{NC}$ to $36 \pm 8$ 
$\mathrm{PR}_{3} / \mathrm{NC}\left(23 \pm 5 \mathrm{Et}_{3} \mathrm{P}\right.$ and $\left.13 \pm 3 \mathrm{Bu}_{3} \mathrm{P}\right)$. At higher concentrations of $\mathrm{Et}_{3} \mathrm{P}$ more $\mathrm{Bu}_{3} \mathrm{P}$ is displaced, however the NCs begin to precipitate from the solution. Similar results were obtained with trimethylphosphine $\left(\mathrm{Me}_{3} \mathrm{P}\right)$. In this case the 1 equiv. of added $\mathrm{Me}_{3} \mathrm{P}$ more completely binds the nanocrystal than $\mathrm{Et}_{3} \mathrm{P}$, achieving an even higher total phosphine coverage; $45 \pm 8$ phosphines per NC.

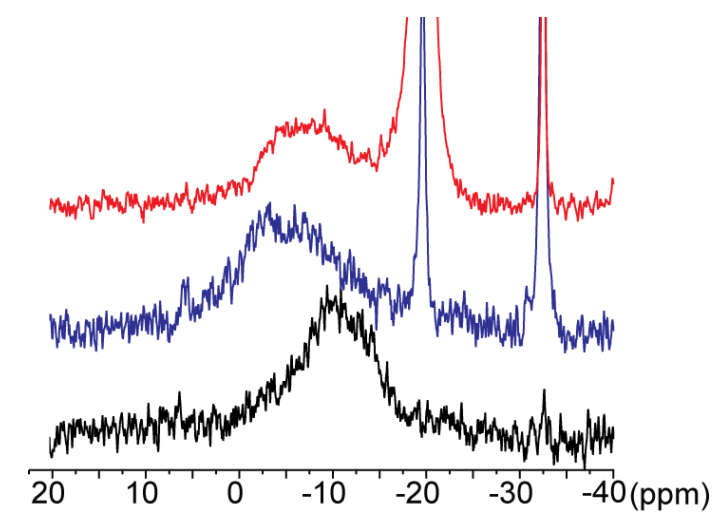

Figure 2. ${ }^{31} \mathrm{P}$ NMR spectra of $\mathbf{C d S e}-\mathbf{C d C l}_{2} / \mathbf{B u}_{3} \mathbf{P}(0.5 \mathrm{mM}$ NCs, $14.8 \mathrm{mM} \mathrm{Bu} 33$, black, bottom) with triethylphosphine $(\delta=-19)$ at 1:1 equivalents (blue) and 50:1 equivalents (red). The new broad resonance at $\delta=-6 \mathrm{ppm}$ is $\mathrm{Et}_{3} \mathrm{P}$ bound to the $\mathrm{NC}$.

We then explored the binding of P,P-dimethyl-n-octylphosphine $\left(\mathrm{Me}_{2} \mathrm{P}-n\right.$-octyl) with the hypothesis that this ligand would provide a stable colloidal dispersion that could be used to measure the coverage of a pure $\mathrm{Me}_{2} \mathrm{P}-n$-octyl ligand shell. Indeed, stable dispersions of $\mathrm{Me}_{2} \mathrm{P}-n$-octyl bound $\mathrm{NCs}\left(\mathbf{C d S e}-\mathbf{C d C l}_{2} / \mathbf{M e}_{2} \mathbf{P}-\boldsymbol{n}\right.$-octyl) could be synthesized by completely displacing $\mathrm{Bu}_{3} \mathrm{P}$ ligands from $\mathbf{C d S e}-\mathrm{CdCl}_{2} / \mathbf{B u} 3 \mathbf{P}$ or upon reaction of $\mathbf{C d S e}-\mathbf{C d}\left(\mathrm{O}_{2} \mathbf{C R}\right)_{2}$, with $\mathrm{Me}_{2} \mathrm{P}-n$-octyl and $\mathrm{Me}_{3} \mathrm{SiCl}$ (see Supporting Information). By either method, the $\mathrm{Me}_{2} \mathrm{P}-n$-octyl surface coverage is $2.0-2.2$ $\mathrm{nm}^{-2}\left(90 \pm 15 \mathrm{Me}_{2} \mathrm{P}-n\right.$-octyl per NC, $d=3.8 \mathrm{~nm}$, see Supporting Information), $\sim 4 \mathrm{x}$ greater than the coverage of $\mathrm{Bu}_{3} \mathrm{P}$ ligands.

A wide range of ligands were surveyed in this manner. The relative affinity of the tri- $n$ alkylphosphines is $\mathrm{Me}_{3} \mathrm{P}>\mathrm{Me}_{2} \mathrm{P}-n$-octyl $>\mathrm{Et}_{3} \mathrm{P}>\mathrm{Bu}_{3} \mathrm{P}$ while the affinity of the amine ligands is 
$\mathrm{H}_{2} \mathrm{NBu}>\mathrm{Bu}_{3} \mathrm{P} \sim \mathrm{HNBu}_{2}>\mathrm{Me}_{2} \mathrm{NBu}>\mathrm{NBu}_{3}$. In addition, a variety of bulky and/or electron deficient ligands displace little or no $\mathrm{Bu}_{3} \mathrm{P}$ from the $\mathrm{NCs}$ even at high concentration, including triethylphosphite, triphenylphosphine, diphenylphosphine, tetradecanol, furan, thiophene, tetrahydrofuran, diethylether, $n$-pentylisocyanide, and di-n-butylsulfide.

To assess the effect of ligand basicity and structure on the displacement reactivity, the $p K_{a}$ of the conjugate acid and the Tolmann cone angle of each ligand are plotted in Figure 3.(29, 30) Ligands that effectively compete with $\mathrm{Bu}_{3} \mathrm{P}$ for the $\mathrm{NC}$ surface are highlighted. Both a small cone angle and a high ligand basicity are key to a high affinity for the surface. Sterically unencumbered ligands with low basicity, such as $n$-pentylisocyanide $\left(p K_{a}\left(\mathrm{R}-\mathrm{N} \equiv \mathrm{C}-\mathrm{H}^{+}\right)=0.86, \mathrm{H}_{2} \mathrm{O}, \mathrm{R}=\right.$ cyclohexyl)(31) do not compete with $\mathrm{Bu}_{3} \mathrm{P}$ for the surface. However, weakly basic ligands with soft donor atoms such as tetrahydrothiophene $\left(p K_{a}\left(\mathrm{Et}_{2} \mathrm{~S}-\mathrm{H}^{+}\right)=-6.7, \mathrm{H}_{2} \mathrm{O}\right)(32)$ displace a small amount of $\mathrm{Bu}_{3} \mathrm{P}$ at high concentration. The special affinity of soft ligands helps explain the poor binding of the hard $\mathrm{Bu}_{3} \mathrm{~N}$ ligand $\left(p K_{a}\left(\mathrm{Et}_{3} \mathrm{~N}-\mathrm{H}^{+}\right)=10.7, \mathrm{H}_{2} \mathrm{O}\right)(32)$, which is a stronger $\mathrm{Br} \varnothing n s t e d$ base than its isostructural phosphine; $\mathrm{Bu}_{3} \mathrm{P}\left(p K_{a}\left(\mathrm{Bu}_{3} \mathrm{P}-\mathrm{H}^{+}\right)=8.4, \mathrm{H}_{2} \mathrm{O}\right)(30) . \mathrm{Bu}_{3} \mathrm{~N}$ also has a greater cone angle than $\mathrm{Bu}_{3} \mathrm{P}$, owing to the shorter $\mathrm{M}-\mathrm{N}$ bond and the larger $\mathrm{C}-\mathrm{E}-\mathrm{C}$ angle, which increases its steric profile. Thus, soft, basic ligands with a small steric profile bind with the greatest affinity. 

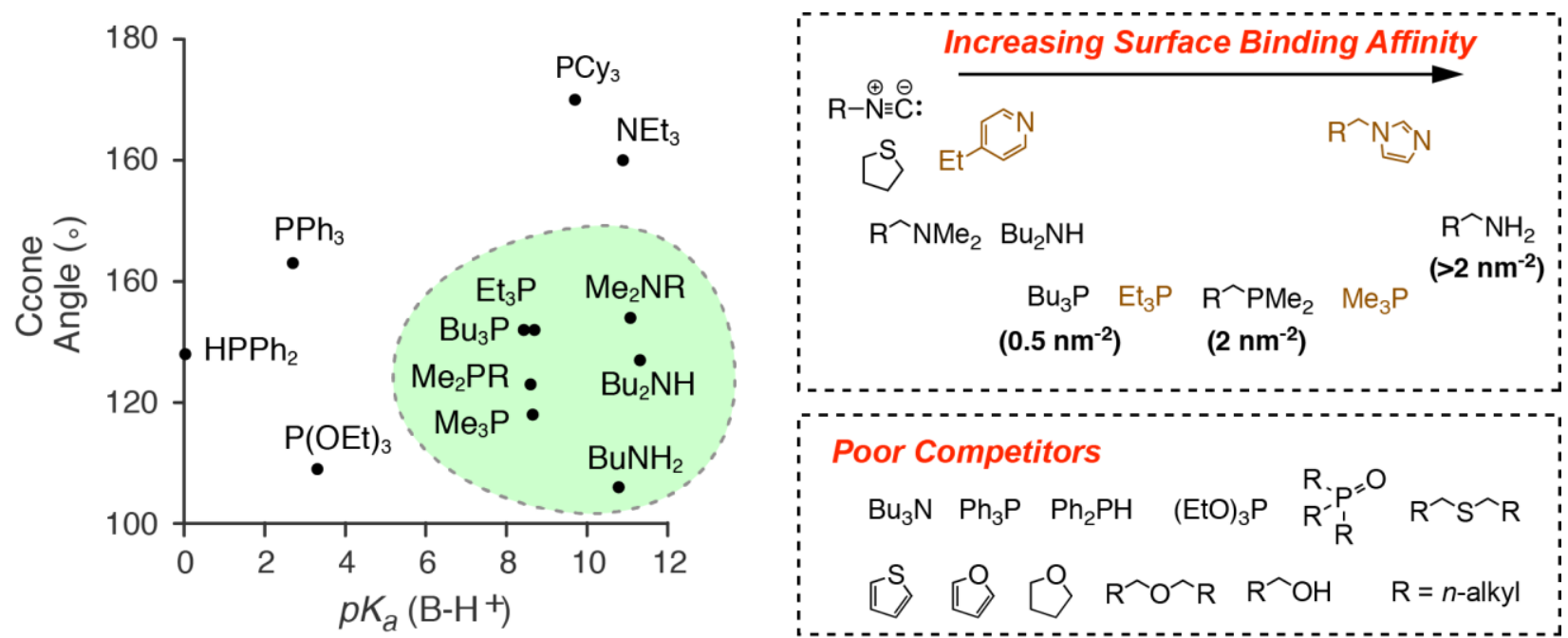

Figure 3. (left) $p K_{a}$ versus Tolmann cone angles for amines and phosphines in the ligand binding series. The green area contains strong binders. (right, top) Relative binding affinities of all molecules studied, with molecules of greatest affinity on the right. Molecules in brown do not support stable colloidal dispersion on their own. (right, bottom) Molecules that do not displace significant quantities of $\mathrm{Bu}_{3} \mathrm{P}$ at high concentration. In all cases, $\mathrm{R}=n$-alkyl.

Pyridine and tri- $n$-octylphosphine oxide (TOPO) have been reported to stabilize nanoparticle dispersions, although recent studies have argued otherwise.(33-36) To shed light on the issue we studied the displacement of $\mathrm{Bu}_{3} \mathrm{P}$ from $\mathbf{C d S e}-\mathbf{C d C l}_{2} / \mathbf{B u} 3 \mathbf{P}$ in pyridine and $\mathrm{TOPO}$ solution. Despite its moderate basicity, pyridine $\left(p K_{a}\left(\right.\right.$ pyridine $\left.\left.-\mathrm{H}^{+}\right)=5.2, \mathrm{H}_{2} \mathrm{O}\right)(37)$ effectively displaces the much more basic and soft $\mathrm{Bu}_{3} \mathrm{P}$ donor ligand. In the presence of 1 equiv. of pyridine, the $\mathrm{NCs}$ begin to precipitate. 4-Ethylpyridine, however, displaces $30 \%$ of the $\mathrm{Bu}_{3} \mathrm{P}$ and maintains a stable dispersion. Higher concentrations of 4-ethylpyridine also induce precipitation. Similar results are observed with 1-butylimidazole, which outcompetes $\mathrm{Bu}_{3} \mathrm{P}$ for the $\mathrm{NC}$ surface and displaces a greater quantity of $\mathrm{Bu}_{3} \mathrm{P}$ than does pyridine, consistent with its greater basicity $\left(p K_{a}\left(\right.\right.$ imidazole $\left.\left.-\mathrm{H}^{+}\right)=7.0, \mathrm{H}_{2} \mathrm{O}\right)$ and small steric profile. TOPO, on the other hand, does not displace $\mathrm{Bu}_{3} \mathrm{P}$, even at high concentrations $(0.3 \mathrm{M})$. Moreover, the reaction of $\mathbf{C d S e}-\mathbf{C d}\left(\mathbf{O}_{2} \mathbf{C R}\right)_{2}$ with $\mathrm{Me}_{3} \mathrm{SiCl}$ in pyridine or TOPO solution caused precipitation of the NCs. We conclude that pyridine and 1-butylimidazole bind the NC surface effectively but do not stabilize a colloidal dispersion, even in a neat solution 
of the ligand. On the other hand, TOPO does not compete with $\mathrm{Bu}_{3} \mathrm{P}$, nor does it stabilize a colloidal dispersion.

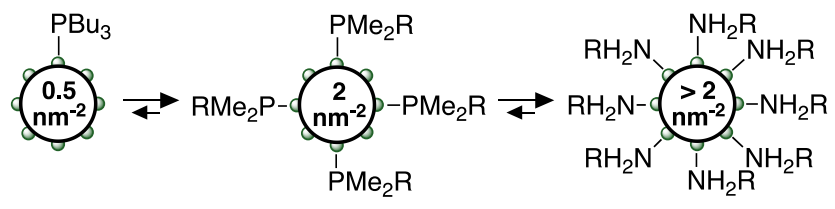

Scheme 2. Areal density of L-type ligands.

The relatively high affinity of the pyridine and imidazole ligands, and the influence of steric properties on the coverage of alkylphosphines suggests that the competitive binding equilibrium is determined by the number of each competitor that binds as well as the relative surface-ligand bond dissociation energy (BDE(S-L)) (Scheme 2). In the case of the alkylphosphines, the coverage of phosphines increases 4 -fold on exchanging $\mathrm{Bu}_{3} \mathrm{P}$ for $\mathrm{Me}_{2} \mathrm{P}-n$-octyl $\left(0.5 \mathrm{~nm}^{-2}\right.$ vs. $\left.2 \mathrm{~nm}^{-2}\right)$. These coverages are insensitive to the solution concentration and are therefore likely near the maximum for these ligands. $n$-Alkylamines, on the other hand, display concentration dependent binding poor colloidal stability is observed as the amine concentration is lowered - and their rapid degenerate exchange prevents the coverage from being directly measured in situ using ${ }^{1} \mathrm{H}$ NMR spectroscopy. A lower bound for their saturation coverage $\left(1.5-5 n\right.$-alkylamines $\left.\mathrm{nm}^{-2}\right)$ can be estimated by precipitating the NCs from concentrated amine solution and drying them under vacuum (see Supporting Information). We conclude that the saturation coverage of $n$-alkylamines is greater than $2 \mathrm{~nm}^{-2}$. Thus, an increased coverage can compensate for a weak surface-ligand interaction, which helps explain the high affinity of relatively weak donors such as pyridine and 1$n$-butylimidazole. On the contrary, strong donors, such as $\mathrm{N}$-heterocylic carbenes $\left(p K_{\mathrm{a}}\left(\mathrm{NHC}-\mathrm{H}^{+}\right)\right.$ 23)(38) may form a strong surface-ligand bond in isolation, but should have low affinity if their substituents are bulky (e.g. mesityl). 
The precipitation caused by displacing $\mathrm{Bu}_{3} \mathrm{P}$ with pyridine confirms a recent study of stoichiometric CdSe NCs.(15) That study suggested that pyridine stabilized dispersions can be aided by acidic impurities that contribute electrostatic stabilization.(10, 39-45) The same study also reported that stoichiometric $\mathrm{CdSe}$ NCs stabilized by $\mathrm{Bu}_{3} \mathrm{P}$ alone $(\mathbf{C d S e}-\mathbf{B u} \mathbf{P})$ were unstable to aggregation, which is at odds with the stability of $\mathbf{C d S e - C d C l}$ /Bu3 $\mathbf{P}$ herein.(15, 25) Interestingly, addition of $\mathrm{CdCl}_{2}$ to $\mathbf{C d S e}-\mathbf{B u}_{3} \mathbf{P}(15)$ leads to the de-aggregation of the NCs and the formation of a clear and stable dispersion that is indistinguishable from the $\mathbf{C d S e}-\mathbf{C d C l}_{2} / \mathbf{B u} 3 \mathbf{P}$ used in this study (See Supporting Information). The origin of this effect is unclear and the subject of current investigations in our lab.

Given the high binding affinities and increased surface coverages of sterically unencumbered ligands observed above, we sought to stabilize stoichiometric $\mathrm{CdSe} \mathrm{NCs}$ in the absence of $\mathrm{CdCl}_{2}$ using $P, P$-dimethyl- $n$-octadecylphosphine ( $\mathrm{Me}_{2} \mathrm{P}$ - $\boldsymbol{n}$-octadecyl). CdSe-Me2P-n-octadecyl was prepared from $\mathbf{C d S e}-\mathrm{NH}_{2} \mathrm{Bu}$ (15) via ligand exchange (see Supporting Information). Addition of $\mathrm{Me}_{2} \mathrm{P}$ - $n$-octadecyl to $\mathbf{C d S e}-\mathbf{N H}_{2} \mathbf{B u}$ in $\mathrm{C}_{6} \mathrm{D}_{6}$ does not displace $n$-butylamine, as expected from the relative binding affinities measured above (Figure 3), until the primary amine is removed under vacuum with heat (See Supporting Information). Binding of the $\mathrm{Me}_{2} \mathrm{P}-n$-octadecyl ligand can be monitored with ${ }^{31} \mathrm{P}$ NMR spectroscopy because CdSe-Me2P-n-octadecyl is characterized by a broad resonance $(\delta=-38 \mathrm{ppm}, \Delta \delta=15-20 \mathrm{ppm})$ that increases in intensity as the amine ligands are desorbed. Following complete removal of $\mathrm{NH}_{2} \mathrm{Bu}$, the $\mathrm{Me}_{2} \mathrm{P}-n$-octadecyl coverage reaches 2 $\mathrm{nm}^{-2}$, similar to the coverage of phosphine ligands in $\mathbf{C d S e - C d C l} / \mathbf{M e}_{2} \mathbf{P}-\boldsymbol{n}$-octyl and $4 \mathrm{x}$ greater than $\mathbf{C d S e}-\mathbf{C d C l}_{2} / \mathbf{B u}_{3} \mathbf{P}$. We conclude that the higher ligand coverage and the long $n$-octadecyl chain provide greater colloidal stability to $\mathrm{CdSe}-\mathbf{M e}_{2} \mathbf{P}-\boldsymbol{n}$-octadecyl compared to $\mathrm{CdSe}-\mathrm{Bu} \mathbf{3}$.

The greater surface binding affinity of $\mathrm{NH}_{2} \mathrm{Bu}$ compared to phosphines may also be explained by their ability to achieve higher surface coverage. In support of this hypothesis, $\mathrm{Me}_{2} \mathrm{P}-n$-octadecyl 
undergoes slow exchange at $\mathbf{C d S e - M e} 2 \mathbf{P}-\boldsymbol{n}$-octadecyl, while amines undergo fast degenerate exchange on the ${ }^{1} \mathrm{H}$ NMR timescale at room temperature.(23, 24). Even at temperatures as high as $390 \mathrm{~K}$ (see supporting information), the average $\mathrm{Me}_{2} \mathrm{P}-n$-octadecyl exchange rate constant is slower than $10^{-3} \mathrm{~s}^{-1}$ (Figures $\mathrm{S} 10$ \& $\mathrm{S} 11$ ). The slow exchange of $\mathrm{Me}_{2} \mathrm{P}-n$-octadecyl suggests it has a greater $\mathrm{BDE}(\mathrm{S}-\mathrm{L})$ than an $n$-alkylamines. Phosphines are known to bind aqueous $\mathrm{Cd}^{2+}$ more tightly than amines. $(46,47)$ Thus, we tentatively conclude that tri-n-alkylphosphine ligands have a greater $\mathrm{BDE}(\mathrm{S}-\mathrm{L})$ than an primary $n$-alkylamine ligands, yet their affinity for the surface is lower because primary $n$-alkylamines achieve higher surface coverages, as depicted in Scheme 2.

In all cases described above, the surface ligand coverages are significantly lower than the aerial density of atoms on the CdSe surface $\left(5.4-6.2 \mathrm{~nm}^{-2}\right)$ and the packing density of crystalline alkane chains $\left(4.9 \mathrm{~nm}^{-2}\right)$. These low coverages suggest that repulsive interactions between ligands can block adjacent binding sites. While surface coverages higher than the areal density of crystalline alkanes or binding sites on the crystal surface are sometimes reported(48) these values may reflect the formation of multi-layers or the presence of free ligands, rather than the number of surfaceligand bonds. On the other hand, the highly curved surfaces of very small NC can accommodate a greater number of surface ligands. For example, pyramidal CdSe clusters with $1.7-2.5 \mathrm{~nm}$ edge lengths have $1.5-2 \mathrm{x}$ increased volume available for their ligands compared to a flat facet, and one benzoate or $n$-butylamine ligand can bind every available coordination site.(49) However, as the particle size increases and the curvature drops, the packing of ligands must drop below that of crystalline $n$-alkanes $\left(4.9 \mathrm{~nm}^{-2}\right)$ and many coordination sites will remain empty. Thus, the high atom density of surfaces will cause steric interactions between ligands that reduces their packing on the NC surface and lowers their surface binding affinity.

Self-assembled monolayers (SAMs) pack with aerial densities $\left(4-4.6 \mathrm{~nm}^{-2}\right)$ just below that of crystalline alkanes.(50-53) On the $\mathrm{Au}(111)$ surface, thiolate SAMs assume high symmetry 
structures that are commensurate with the underlying lattice, but much less densely packed (4.6 $\mathrm{nm}^{-2}$ ) than the surface atoms $\left(12\right.$ atoms $\left./ \mathrm{nm}^{-2}\right)$. Van der Waals interactions between chains within the SAM strengthen the binding and increase as the chain length grows. $(54,55)$ Similarly, the $\operatorname{Si}(111)$ surface has an aerial density of atop sites $\left(7.8 \mathrm{~nm}^{-2}\right)$ greater than the maximum packing density of alkane chains. Each of these sites can be terminated by a $\mathrm{Si}-\mathrm{H}$ or $\mathrm{Si}-\mathrm{Me}$ bond, however larger functional groups, such as ethyl, do not form a complete monolayer.(56) Moreover, theoretical and experimental work has shown that the rotation of methyl groups on $\mathrm{Si}(111)$ is hindered by steric interactions with neighboring methyls.(57) In both cases interactions between neighboring ligands dictate the coverage and structure of these surface layers. On the surfaces of II-VI and III-V NCs, the areal densities are equal or lower than Si (111), but still greater than the crystalline alkanes in most cases. Even straight chain ligands such as $\mathrm{NH}_{2} \mathrm{Bu}$ will not bind every available site as the surfaces grow beyond a few nanometers. Branched ligands (e.g. $\left.\mathrm{Bu}_{3} \mathrm{P}\right)$, can therefore be expected to prohibit the binding of neighboring ligands and influence the coverages as demonstrated above. The steric influence on the coverage must therefore be considered when predicting the relative surface binding affinities of L-type ligands.

\section{Conclusion}

The stereo-electronic properties of amines and phosphines were surveyed using competitive binding experiments. Soft, electron-rich donor ligands bind the surface most tightly making phosphines better ligands than the isostructural amine. However, the ligand coverage is sensitive to its steric bulk and $6 \mathrm{x}-8 \mathrm{x}$ greater number of $\mathrm{NH}_{2} \mathrm{Bu}$ ligands bind the nanocrystal than do $\mathrm{Bu}_{3} \mathrm{P}$ ligands. The large difference in the number of surface-ligand bonds has a significant impact on the competitive binding equilibrium. Hence a strong Lewis base may therefore be readily displaced from the surface by weaker Lewis base with a smaller steric profile. The impact of steric bulk on 
the coverage and competitive binding is expected for all the binary semiconductors, whose surface atoms are more densely packed than crystalline alkane chains, particularly as the nanocrystal grows larger than a few nm.

\section{Acknowledgements}

This work was supported by the Department of Energy (Grant No. DE-SC0006410). Nick Anderson and Peter Chen were supported by National Science Foundation Graduate Research Fellowships (Grant No. DGE07-07425 and DEG11-44155). Jonathan De Roo acknowledges support from the Belgian American Education Foundation (BAEF), Fulbright and the European Union's Framework Program for Research and Innovation Horizon 2020 (2014-2020) under the Marie Skłodowska-Curie Grant Agreement COMPASS No. 691185. The authors acknowledge Ponisseril Somasundaran for helpful discussions. 


\section{Methods}

General Considerations. All manipulations were performed using standard Schlenk techniques or within a nitrogen atmosphere glovebox unless otherwise indicated. Pentane, toluene, methyl acetate, diethyl ether and tetrahydrofuran were purchased anhydrous from Sigma Aldrich and shaken over activated alumina, filtered, and stored over $4 \AA$ molecular sieves in an inert atmosphere glovebox at least $24 \mathrm{~h}$ prior to use. Diphenylphosphine (99\%), $N, N,{ }^{\prime} N,{ }^{\prime} N$-tetramethylethylene-1,2diamine (TMEDA) (98\%), triethylphosphite (99\%), tri- $n$-octylphosphine (97\%), triethylphosphine (99\%), and tri- $n$-butylphosphine (99\%) were purchased from Strem and used without further purification. $\mathrm{CdMe}_{2}$ was purchased from Strem and vacuum distilled prior to use. CAUTION: Dimethylcadmium is extremely toxic and because of its volatility and air-sensitivity should only be handled by a highly trained and skilled scientist. N,N-Dimethylbutylamine (98\%), furan (99\%), thiophene (98\%), $n$-butylamine (98\%), di- $n$-butylamine (98\%), trimethylphosphine (99\%), , $n$ pentylisocyanide, di- $n$-butylsulifide (98\%), trichloromethylsilane (98\%), tri- $n$-butylamine (99\%), $n$-octylamine $(99 \%)$, benzene- $d_{6}(99.9 \%)$ and pyridine $(99.5 \%)$ were purchased from Sigma Aldrich and dried over $\mathrm{CaH}_{2}$, distilled, and stored in a nitrogen glovebox. Toluene- $d_{8}$ was purchased from Cambridge Isotopes and dried over $\mathrm{CaH}_{2}$, distilled, and stored in a nitrogen glovebox. Tri- $n$-octylphosphine oxide (99\%) was purchased from Sigma Aldrich and recrystallized from acetonitrile as reported previously.(34)

$\mathrm{CdSe}-\mathrm{Cd}\left(\mathrm{O}_{2} \mathrm{CR}\right)_{2}$. Carboxylate terminated $\mathrm{CdSe} \mathrm{NCs}\left(\mathrm{CdSe}-\mathrm{Cd}\left(\mathrm{O}_{2} \mathrm{CR}\right)_{2}\right)$ are synthesized and treated with $\mathrm{Me}_{2} \mathrm{Cd}$ to remove acidic impurities as previously described.(58)

$\mathbf{C d S e}-\mathbf{C d C l}_{2} / \mathbf{B u} 3 \mathbf{P}$. All manipulations are conducted on a Schlenk line at room temperature. In a typical synthesis, a benzene- $d_{6}$ stock solution of $\mathbf{C d S e}-\mathbf{C d}\left(\mathbf{O}_{2} \mathbf{C R}\right)_{2}(1.0 \mathrm{ml}, 0.5-2.0$ mmolar carboxylate, $[\mathrm{CdSe}]=1.6-6.5 \mathrm{mmolar},[\mathrm{NC}]=4-16 \mu$ molar) was transferred to a $50 \mathrm{ml}$ Schlenk tube with a magnetic stir bar. The solution was diluted to a total volume of $5 \mathrm{ml}$ with toluene to which $\mathrm{Bu}_{3} \mathrm{P}(0.506 \mathrm{~g}, 0.624 \mathrm{ml}, 2.5 \mathrm{mmol})$ was added. $\mathrm{Me}_{3} \mathrm{Si}-\mathrm{Cl}(6.0-24 \mathrm{mmol}, 12$ equiv. $)$ was added and the solution stirred for 24 hours. After this time, the volatiles were removed under vacuum and the red solid dissolved in pentane $(5 \mathrm{ml})$ and a methyl acetate was added to precipitate the nanocrystals, which were separated by centrifugation (7000 RPM for 5 minutes). This process was repeated twice more, after which the red powder was dried overnight under vacuum. The nanocrystals were dispersed in benzene- $d_{6}$ to a CdSe concentration of $0.5-1.0 \mathrm{M}$, as described previously.(16)

Competitive Displacement of Bu3P from $\mathbf{C d S e}-\mathbf{C d C l}_{2} / \mathbf{B u} 3 \mathbf{P}$. Benzene- $d_{6}$ stock solutions of various competitor ligands are prepared in a nitrogen filled glove box by diluting the ligand (0.9 mmole) with benzene- $d_{6}(1 \mathrm{ml})$. Using a $25 \mu \mathrm{l}$ syringe, $10 \mu \mathrm{l}$ of this stock solution $(9 \mu$ moles of ligand) is added to a benzene- $d_{6}$ solution of $\mathbf{C d S e}-\mathbf{C d C l}_{2} / \mathbf{B u} \mathbf{u}_{3} \mathbf{P}\left(600 \mu \mathrm{l}, 15 \mathrm{mM}\right.$ in $\mathrm{Bu}_{3} \mathrm{P}, 0.6 \mathrm{mM}$ in $\mathrm{NC}$ ) in a J-young $\mathrm{NMR}$ tube to form an equimolar solution of the added ligand and $\mathrm{Bu}_{3} \mathrm{P}$. ${ }^{31} \mathrm{P}\left\{{ }^{1} \mathrm{H}\right\}$ and ${ }^{1} \mathrm{H}$ NMR spectra are acquired within 1 hour $\left({ }^{31} \mathrm{P}\left\{{ }^{1} \mathrm{H}\right\}: 2\right.$ sec delay with $0.1 \mathrm{sec}$ acquisition, $800 \mathrm{scans} ;{ }^{1} \mathrm{H}$ : $30 \mathrm{sec}$ delay with $5 \mathrm{sec}$ acquisition, 16 scans). The J-young tube is then transferred to a nitrogen filled glove box where the appropriate mass of neat ligand is added to bring the total concentration of ligand to $0.75 \mathrm{M}$ (50 equiv.). The J-young tube is then sealed and ${ }^{31} \mathrm{P}\left\{{ }^{1} \mathrm{H}\right\}$ and ${ }^{1} \mathrm{H}$ NMR spectra are acquired as described above. In some cases the procedure is reapeated to bring the concentration of competitor ligand to $1.5 \mathrm{M}$ (100 equiv.). 
$\boldsymbol{P}, \boldsymbol{P}$-Dimethyl- $\boldsymbol{n}$-octylphosphine. $P, P$-dimethyl- $n$-octylphosphine was prepared on 19.7 mmole scale from $n$-octylmagnesium bromide and chlorodimethylphosphine as previously described.(59) ${ }^{31} \mathrm{P}\left\{{ }^{1} \mathrm{H}\right\} \mathrm{NMR}\left(\mathrm{C}_{6} \mathrm{D}_{6}, 162 \mathrm{MHz}\right): \delta=-55 \mathrm{ppm}$, (chloroform- $\left.d, 162 \mathrm{MHz}\right): \delta=-51 \mathrm{ppm} .{ }^{1} \mathrm{H} \mathrm{NMR}$ (chloroform- $d, 400 \mathrm{MHz}): \delta=0.89\left(\mathrm{~d}, 6 \mathrm{H},-\mathrm{CH}_{3}\right), 0.91\left(\mathrm{t}, 3 \mathrm{H},-\mathrm{CH}_{3}\right) 1.2-1.6\left(\mathrm{~b}, 12 \mathrm{H},-\mathrm{CH}_{2}\right), 1.59$ $\left(\mathrm{m}, 2 \mathrm{H}, \beta-\mathrm{CH}_{2}\right), 1.98\left(\mathrm{~m}, 2 \mathrm{H},-\mathrm{PCH}_{2}\right) .{ }^{31} \mathrm{P}\left\{{ }^{1} \mathrm{H}\right\} \mathrm{NMR}(\mathrm{s})$.

Synthesis of CdSe-CdCl$/ \mathbf{M e}_{2} \mathrm{P}-\boldsymbol{n}$-octyl. All manipulations were conducted on a Schlenk line at room temperature. In a typical synthesis, a benzene- $d_{6}$ stock solution of $\mathbf{C d S e}-\mathbf{C d}\left(\mathbf{O}_{2} \mathbf{C R}\right)_{2}(1.0$ $\mathrm{ml}, 0.5-2.0 \mathrm{mmol}$ ligand) with a known carboxylate concentration was transferred to a $50 \mathrm{ml}$ Schlenk tube with a magnetic stir bar. The solution was diluted to a total volume of $5 \mathrm{ml}$ with toluene to which $\mathrm{Me}_{2} \mathrm{POc}(0.438 \mathrm{~g}, 2.5 \mathrm{mmol})$ was added. $\mathrm{Me}_{3} \mathrm{Si}-\mathrm{Cl}(0.651-2.607 \mathrm{~g}, 6.0-24$ mmol, 12 equiv.) was added and the solution stirred for 24 hours. After this time, the volatiles were distilled off under vacuum and the red solid dissolved in toluene $(5 \mathrm{ml})$ and methyl acetate was added to precipitate the nanocrystals, which were separated by centrifugation (7000 RPM for 5 minutes). This process was repeated twice more, after which the red powder was dried overnight under vacuum. The nanocrystals were diluted in toluene- $d_{8}$ to $[\mathrm{NC}]=0.5-1.0 \mathrm{mM}$ and analyzed ${ }^{31} \mathrm{P}\left\{{ }^{1} \mathrm{H}\right\}$ and ${ }^{1} \mathrm{H}$ NMR spectroscopies.

\section{Supporting Information}

Variable temperature NMR spectroscopy of $\mathrm{CdSe}-\mathrm{CdCl}_{2} / \mathrm{Me}_{2} \mathrm{P}-n$-octyl, the synthesis of $\mathrm{CdSe}$ $\mathrm{CdCl}_{2} / \mathrm{PBu}_{3}$ from $\mathrm{CdSe}-\mathrm{NH}_{2} \mathrm{Bu}$, the synthesis of $P, P$-dimethyl- $n$-octadecylphosphine and the synthesis of $\mathrm{CdSe}-P, P$-dimethyl- $n$-octadecylphosphine are described in the supporting information.

\section{References}

1. Owen J (2015) The coordination chemistry of nanocrystal surfaces. Science 347(6222):615-616.

2. Munro AM, Plante IJ-1, Ng MS, \& Ginger DS (2007) Quantitative Study of the Effects of Surface Ligand Concentration on CdSe Nanocrystal Photoluminescence. Journal of Physical Chemistry C 33:6220-6227.

3. Kalyuzhny G \& Murray RW (2005) Ligand effects on optical properties of CdSe nanocrystals. The journal of physical chemistry. B 109:7012-7021.

4. Jasieniak J \& Mulvaney P (2007) From Cd-rich to Se-rich - The manipulation of CdSe nanocrystal surface stoichiometry. Journal of the American Chemical Society 129(10):2841-2848.

5. Galian RE \& Scaiano JC (2009) Fluorescence quenching of CdSe quantum dots by tertiary amines and their surface binding effect. Photochem. Photobiol. Sci. 8(1):70-74.

6. Gomez DE, van Embden J, Jasieniak J, Smith TA, \& Mulvaney P (2006) Blinking and surface chemistry of single CdSe nanocrystals. Small 2(2):204-208.

7. Bawendi MG, Carroll PJ, Wilson WL, \& Brus LE (1992) LUMINESCENCE PROPERTIES OF CDSE QUANTUM CRYSTALLITES - RESONANCE BETWEEN INTERIOR AND SURFACE LOCALIZED STATES. J. Chem. Phys. 96(2):946-954.

8. Murray CB, Norris DJ, \& Bawendi MG (1993) Nanocrystallites, Te Semiconductor. Journal of the American Chemical Society 115:8706-8715.

9. Busby E, Anderson NC, Owen JS, \& Sfeir MY (2015) Effect of Surface Stoichiometry on Blinking and Hole Trapping Dynamics in CdSe Nanocrystals. Journal of Physical Chemistry C 119(49):27797-27803. 
10. Guyot-Sionnest P, Shim M, Matranga C, \& Hines M (1999) Intraband relaxation in CdSe quantum dots. Phys. Rev. B 60(4):R2181-R2184.

11. Meeker K \& Ellis AB (1999) Adsorption of Alkanolamines onto Semiconductor Surfaces: Cadmium Selenide Photoluminescence as a Probe of Binding and Film Reactivity toward Carbon Dioxide. The Journal of Physical Chemistry B 103(6):995-1001.

12. Meyer GJ, Lisensky GC, \& Ellis AB (1988) Evidence for Adduct Formation at the Semiconductor Gas Interface - Photoluminescent Properties of Cadmium Selenide in the Presence of Amines. Journal of the American Chemical Society 110(15):4914-4918.

13. Murphy CJ \& Ellis AB (1990) The coordination of mono- and diphosphines to the surface of cadmium selenide. Polyhedron 9(15):1913-1918.

14. Bullen C \& Mulvaney P (2006) The effects of chemisorption on the luminescence of CdSe quantum dots. Langmuir 22(7):3007-3013.

15. Chen PE, Anderson NC, Norman ZM, \& Owen JS (2017) Tight Binding of Carboxylate, Phosphonate, and Carbamate Anions to Stoichiometric CdSe Nanocrystals. Journal of the American Chemical Society 139(8):3227-3236.

16. Anderson NC, Hendricks MP, Choi JJ, \& Owen JS (2013) Ligand Exchange and the Stoichiometry of Metal Chalcogenide Nanocrystals: Spectroscopic Observation of Facile Metal-Carboxylate Displacement and Binding. Journal of the American Chemical Society 135(49):18536-18548.

17. Fritzinger B, Capek RK, Lambert K, Martins JC, \& Hens Z (2010) Utilizing Self-Exchange To Address the Binding of Carboxylic Acid Ligands to CdSe Quantum Dots. Journal of the American Chemical Society 132(29):10195-10201.

18. De Roo J, Van Driessche I, Martins JC, \& Hens Z (2016) Colloidal metal oxide nanocrystal catalysis by sustained chemically driven ligand displacement. Nat Mater 15(5):517-521.

19. Valdez CN, Schimpf AM, Gamelin DR, \& Mayer JM (2014) Low Capping Group Surface Density on Zinc Oxide Nanocrystals. ACS Nano 8(9):9463-9470.

20. Green MLH \& Parkin G (2014) Application of the Covalent Bond Classification Method for the Teaching of Inorganic Chemistry. J. Chem. Educ. 91(6):807-816.

21. Green MLH (1995) A NEW APPROACH TO THE FORMAL CLASSIFICATION OF COVALENT COMPOUNDS OF THE ELEMENTS. J. Organomet. Chem. 500(1-2):127-148.

22. De Roo J, De Keukeleere K, Hens Z, \& Van Driessche I (2016) From ligands to binding motifs and beyond; the enhanced versatility of nanocrystal surfaces. Dalton Trans 45(34):13277-13283.

23. Ji XH, Copenhaver D, Sichmeller C, \& Peng XG (2008) Ligand bonding and dynamics on colloidal nanocrystals at room temperature: The case of alkylamines on CdSe nanocrystals. Journal of the American Chemical Society 130(17):5726-5735.

24. Fritzinger B, et al. (2009) In Situ Observation of Rapid Ligand Exchange in Colloidal Nanocrystal Suspensions Using Transfer NOE Nuclear Magnetic Resonance Spectroscopy. Journal of the American Chemical Society 131(8):3024-3032.

25. Anderson NC \& Owen JS (2013) Soluble, Chloride-Terminated CdSe Nanocrystals: Ligand Exchange Monitored by H-1 and P-31 NMR Spectroscopy. Chem. Mat. 25(1):69-76.

26. Goyal A, et al. (2005) Irradiation-free, columnar defects comprised of self-assembled nanodots and nanorods resulting in strongly enhanced flux-pinning in YBa2Cu3O7-delta films. Supercond. Sci. Technol. 18(11):1533-1538.

27. Anonymous ((At equimolar amine, a broadened signal appears at a chemical shift between free and surface bound phosphine that we tentatively assign to Bu3P ligands in rapid exchange with a fraction of the surface bound phosphines. However, this interpretation is complicated by Bu3P complexes of $\mathrm{CdCl} 2$ that are also present in the reaction mixture (see ref. X). ).

28. Trotman-Dickenson AF (1949) The Basic Strength of Amines. J Chem Soc (May):1293-1297.

29. Brown TL \& Lee KJ (1993) Ligand steric properties. Coordination Chemistry Reviews 128(1):89116. 
30. Rahman MM, Liu HY, Eriks K, Prock A, \& Giering WP (1989) Quantitative analysis of ligand effects. Part 3. Separation of phosphorus(III) ligands into pure .sigma.-donors and sigma.donor/.pi.-acceptors. Comparison of basicity and .sigma.-donicity. Organometallics 8(1):1-7.

31. Sung KS \& Chen CC (2001) Kinetics and mechanism of acid-catalyzed hydrolysis of cyclohexyl isocyanide and $\mathrm{pK}(\mathrm{a})$ determination of N-cyclohexylnitrilium ion. Tetrahedron Lett 42(29):48454848.

32. Laurence C \& Gal J-Fo (2010) Lewis basicity and affinity scales : data and measurement (John Wiley, Chichester, West Sussex, U.K.) pp xv, 460 p., 412 p. of plates.

33. Owen JS, Park J, Trudeau P-E, \& Alivisatos aP (2008) Reaction chemistry and ligand exchange at cadmium-selenide nanocrystal surfaces. Journal of the American Chemical Society 130:1227912281.

34. Kopping JT \& Patten TE (2008) Identification of acidic phosphorus-containing ligands involved in the surface chemistry of CdSe nanoparticles prepared in tri-N-octylphosphine oxide solvents. Journal of the American Chemical Society 130:5689-5698.

35. Wang F, Tang R, \& Buhro WE (2008) The Trouble with TOPO; Identification of Adventitious Impurities Beneficial to the Growth of Cadmium Selenide Quantum Dots, Rods, and Wires. Nano Letters 8(10):3521-3524.

36. Wang F, Tang R, Kao JL-F, Dingman SD, \& Buhro WE (2009) Spectroscopic identification of trin-octylphosphine oxide (TOPO) impurities and elucidation of their roles in cadmium selenide quantum-wire growth. Journal of the American Chemical Society 131:4983-4994.

37. Bordwell FG (1988) Equilibrium Acidities in Dimethyl-Sulfoxide Solution. Accounts of Chemical Research 21(12):456-463.

38. Amyes TL, Diver ST, Richard JP, Rivas FM, \& Toth K (2004) Formation and stability of Nheterocyclic carbenes in water: The carbon acid pK(a) of imidazollum cations in aqueous solution. Journal of the American Chemical Society 126(13):4366-4374.

39. Hanrath T, et al. (2009) PbSe Nanocrystal Network Formation during Pyridine Ligand Displacement. ACS applied materials \& interfaces 1(2):244-250.

40. Leatherdale CA, et al. (2000) Photoconductivity in CdSe quantum dot solids. Phys. Rev. B 62(4):2669-2680.

41. Sun YG \& Rogers JA (2007) Inorganic semiconductors for flexible electronics. Adv. Mater. 19(15):1897-1916.

42. Tang JA \& Sargent EH (2011) Infrared Colloidal Quantum Dots for Photovoltaics: Fundamentals and Recent Progress. Adv. Mater. 23(1):12-29.

43. Tisdale WA, et al. (2010) Hot-Electron Transfer from Semiconductor Nanocrystals. Science 328(5985):1543-1547.

44. Yu D, Wang CJ, Wehrenberg BL, \& Guyot-Sionnest P (2004) Variable range hopping conduction in semiconductor nanocrystal solids. Physical Review Letters 92(21):216802.

45. Zillner E, et al. (2012) Role of Ligand Exchange at CdSe Quantum Dot Layers for Charge Separation. Journal of Physical Chemistry C 116(31):16747-16754.

46. Ahrland S, Chatt J, Davies NR, \& Williams AA (1958) The Relative Affinities of an Amine, an Organic Phosphine, and a Sulphide for Cadmium Ion. J Chem Soc (Apr):1403-1405.

47. Ahrland S, Chatt J, \& Davies NR (1958) The Relative Affinities of Ligand Atoms for Acceptor Molecules and Ions. $Q$ Rev Chem Soc 12(3):265-276.

48. Smith AM, Johnston KA, Crawford SE, Marbella LE, \& Millstone JE (2017) Ligand density quantification on colloidal inorganic nanoparticles. Analyst 142(1):11-29.

49. Beecher AN, et al. (2014) Atomic Structures and Gram Scale Synthesis of Three Tetrahedral Quantum Dots. Journal of the American Chemical Society 136(30):10645-10653.

50. Strong L \& Whitesides GM (1988) Structures of Self-Assembled Monolayer Films of Organosulfur Compounds Adsorbed on Gold Single-Crystals - Electron-Diffraction Studies. Langmuir 4(3):546558. 
51. Offord DA \& Griffin JH (1993) Kinetic Control in the Formation of Self-Assembled Mixed Monolayers on Planar Silica Substrates. Langmuir 9(11):3015-3025.

52. Offord DA, Leonard WG, \& Griffin JH (1993) Self-Assembled Mixed Monolayers of Long-Chain and Very Short-Chain Adsorbates on Silica and Gold Surfaces. Abstr Pap Am Chem S 205:219Orgn.

53. Ulman A (1996) Formation and structure of self-assembled monolayers. Chem Rev 96(4):15331554.

54. Folkers JP, Laibinis PE, \& Whitesides GM (1992) Self-Assembled Monolayers of Alkanethiols on Gold - Comparisons of Monolayers Containing Mixtures of Short-Chain and Long-Chain Constituents with Ch3 and Ch2oh Terminal Groups. Langmuir 8(5):1330-1341.

55. Somasundaran P \& Huang L (2000) Adsorption/aggregation of surfactants and their mixtures at solid-liquid interfaces. Adv Colloid Interfac 88(1-2):179-208.

56. Wong KT \& Lewis NS (2014) What a Difference a Bond Makes: The Structural, Chemical, and Physical Properties of Methyl-Terminated Si(111) Surfaces. Accounts of Chemical Research 47(10):3037-3044.

57. Malyk S, Shalhout FY, O'Leary LE, Lewis NS, \& Benderskii AV (2013) Vibrational Sum Frequency Spectroscopic Investigation of the Azimuthal Anisotropy and Rotational Dynamics of Methyl-Terminated Silicon(111) Surfaces. Journal of Physical Chemistry C 117(2):935-944.

58. Yang YA, Wu H, Williams KR, \& Cao YC (2005) Synthesis of CdSe and CdTe Nanocrystals without Precursor Injection. Angewandte Chemie International Edition 44(41):6712-6715.

59. Marsi KL (1969) Stereochemistry of some reactions of phospholane derivatives. Journal of the American Chemical Society 91(17):4724-4729. 